\title{
Effect of styrene oxide and diethyl maleate on expression of cytochrome P450 family 1 and glutathione store in mouse liver
}

\author{
Waranya Chatuphonprasert ${ }^{1,2}$, Kanokwan Jarukamjorn ${ }^{2 *}$ \\ ${ }^{1}$ Faculty of Medicine, Mahasarakham University, Maha Sarakham 44000, ${ }^{2}$ Research Group for Pharmaceutical Activities of \\ Natural Products using Pharmaceutical Biotechnology Research Group, Faculty of Pharmaceutical Sciences, Khon Kaen \\ University, Khon Kaen 40002, Thailand
}

*For correspondence: Email: kanokwan.ja@kkumail.com; Tel: +66 43202378

Sent for review: 3 September 2020

Revised accepted: 23 January 2021

\begin{abstract}
Purpose: To determine the effect of the glutathione (GSH) suppressors styrene oxide (SO) and diethyl maleate (DEM) on the hepatic expression of cytochrome P450 family 1 (Cyp1) isoforms that are related to carcinogenesis including Cyp1a1, Cyp1a2, and Cyp1b1.

Methods: Seven-week-old ICR mice were intraperitoneally injected with SO (150 and $300 \mathrm{mg} / \mathrm{kg} / \mathrm{day})$, DEM (175 and $350 \mathrm{mg} / \mathrm{kg} / \mathrm{day}$ ), or $\mathrm{N}$-acetylcysteine (NAC; 300 and $600 \mathrm{mg} / \mathrm{kg} /$ day) for 7, 14, or 28 days. Plasma alanine aminotransferase $(A L T)$ and aspartate aminotransferase (AST) levels, hepatic Cyp1 expression, total glutathione, reduced glutathione (GSH), and oxidized glutathione (GSSG) were determined.

Results: ALT and AST levels were markedly increased by SO and DEM while GSH/GSSG ratio was decreased by $S O$ in all treatments $(p<0.05)$, while high dose $(350 \mathrm{mg} / \mathrm{kg} /$ day) $D E M$ significantly suppressed GSH/GSSG ratio at 28 days ( $p<0.05)$. The expressions of Cyp1a1, Cyp1a2, and Cyp1b1 were induced by SO and DEM, corresponding with induction of ethoxy/methoxy-resorufin O-dealkylase activities.

Conclusion: The Cyp1 family metabolizes procarcinogens to carcinogenic DNA adducts; exposure to the industrial solvents, SO and DEM, raises the risk of carcinogenesis via GSH depletion coupled with Cyp1 induction.
\end{abstract}

Keywords: GSH, Carcinogenesis, Diethyl maleate, N-acetylcysteine, Cytochrome P450 family 1, Hepatotoxicity

This is an Open Access article that uses a fund-ing model which does not charge readers or their institutions for access and distributed under the terms of the Creative Commons Attribution License (http://creativecommons.org/licenses/by/4.0) and the Budapest Open Access Initiative (http://www.budapestopenaccessinitiative.org/read), which permit unrestricted use, distribution, and reproduction in any medium, provided the original work is properly credited.

Tropical Journal of Pharmaceutical Research is indexed by Science Citation Index (SciSearch), Scopus, International Pharmaceutical Abstract, Chemical Abstracts, Embase, Index Copernicus, EBSCO, African Index Medicus, JournalSeek, Journal Citation Reports/Science Edition, Directory of Open Access Journals (DOAJ), African Journal Online, Bioline International, Open-J-Gate and Pharmacy Abstracts

\section{INTRODUCTION}

A wide array of xenobiotics can cause cellular damage and affect cellular protective systems depending on their concentrations and the period of exposure. Glutathione (GSH) is a stably controlled antioxidant that is present both intracellularly and extracellularly [1]. Some chemicals such as diethyl maleate (DEM), carbon tetrachloride, acetaminophen, and chloroform are metabolized to mercapturic acid derivatives, which are then detoxified by GSH 
and glutathione-S-transferase leading to GSH depletion in tissue stores [2].

Extensive research has shown a relationship between imbalance in GSH stores and cancer or disease. Chloroform-induced hepatotoxicity progresses from GSH depletion to GSH deficiency, which subsequently results in cell Iysis [3]. Moreover, GSH depletion has been shown to potentiate the toxicity of the anti-cancer drugs cisplatin and melphalan, and to affect dopamine toxicity in the brain [4]. Therefore, GSH depletion can cause damage to multiple cell types and organs.

Cytochrome P450 (CYP) is a super family of hepatic enzymes responsible for the metabolism of drugs and other xenobiotics into water-soluble compounds for excretion. Therefore, the study of CYP expression has been developed and used to predict and explain the toxicology of drugs and xenobiotics [5]. Disruption of the oxidative protective system, such as depletion of GSH stores, affects the metabolism of xenobiotics. Although the toxic effects of GSH depletion have been reported, the impact of GSH depletion on the expression of CYP1 remains unclear. Therefore, we investigated the effect of $\mathrm{GSH}$ depletion on the expression of the carcinogenesis-associated CYP 1 isoforms, Сур1a1, Сyp1a2, and Сyp1b, in mouse livers.

\section{EXPERIMENTAL}

\section{Chemicals}

Diethyl maleate (DEM), styrene oxide (SO), Nacetylcysteine (NAC), reduced glutathione (GSH), and oxidized glutathione (GSSG) were from Sigma-Aldrich Chemical (Steinheim, Germany). Taq-polymerase, reverse transcriptase, ribonuclease inhibitor, dNTP mixture, and other reagents for quantitative reverse transcription PCR (RT-qPCR) were products of Applied Biosystems (Branchburg, NJ, USA) and Toyobo Co. Ltd. (Osaka, Japan).

\section{Animal studies}

Male seven-week-old ICR mice were provided by the National Laboratory Animal Center of Thailand. All animal experiments were performed in the Animal Unit of Faculty of Pharmaceutical Sciences, Khon Kaen University. All protocols were approved by the Animal Ethics Committee for Use and Care, Khon Kaen University (approval no. AEKKU 93/2555), and the study was conducted in accordance with the Declaration of Helsinki and the Guide for the Care and Use of Laboratory Animals [6].
Mice ( $n=4$ - 6 per group) were intraperitoneally (i.p.) injected daily with 150 or $300 \mathrm{mg} / \mathrm{kg} /$ day of styrene oxide (SO), 175 or $350 \mathrm{mg} / \mathrm{kg} /$ day of diethyl maleate (DEM), or 300 or $600 \mathrm{mg} / \mathrm{kg} / \mathrm{day}$ of $\mathrm{N}$-acetylcysteine (NAC) for 7, 14, and 28 days. Twenty-four hours after the last treatment, the mice were anaesthetized with pentobarbital sodium at a dose of $100 \mathrm{mg} / \mathrm{kg}$. The abdominal tissue was removed. Whole blood was collected from inferior vena cava using an IV catheter and a heparin syringe. The whole blood $(0.5-0.8 \mathrm{~mL})$ was centrifuged at $825 \times \mathrm{g}$ for $10 \mathrm{~min}$ at $4^{\circ} \mathrm{C}$ to obtain plasma $(80-100 \mu \mathrm{L})$. The liver was immediately removed for further studies.

\section{Determination of plasma alanine- and aspartate-aminotransferase (ALT and AST)}

Plasma ALT and AST levels were determined using the $\alpha$-ketoglutarate reaction with some modifications [7]. The final reaction mix of plasma with $\alpha$-ketoglutarate and either $L$-alanine for $A L T$, or $\alpha$-ketoglutarate and $L$-aspartate was incubated for AST, at $37{ }^{\circ} \mathrm{C}$ for $30 \mathrm{~min}$. Then, 2,4-dinitrophenylhydrazine and sodium hydroxide were added. The UV- absorbance (505 nm) was measured. The amount of ALT or AST in international units (IU/L) was calculated from a pyruvate standard curve.

\section{Determination of glutathione profiles}

Liver homogenates were prepared in cold sulfosalicylic acid as previously described [7]. The supernatants were analyzed for GSH or GSSG content using 5,5'-dithiobis (2nitrobenzoic acid) thiol formation. For GSSG assay, the sample supernatant was treated with 4-vinylpyridine before performing the assay. Thiol formation was measured at a wavelength of 405 $\mathrm{nm}$ every $1 \mathrm{~min}$ until the kinetic curve was saturated (5 - $10 \mathrm{~min})$. The slope ( $\Delta \mathrm{Abs}_{405} / \Delta$ time) of GSH or GSSG content was calculated and compared to the slope of GSH or GSSG standard curve.

\section{Determination of the expression of hepatic CYP1 mRNA}

Hepatic total RNA was extracted with acid guanidinium thiocyanate-phenol-chloroform, then reverse-transcribed to cDNA. The mRNA expression of Cyp1 mRNA was quantified using RT-qPCR. The levels of Cyp1a1 (Mm00487218_m1), Cyp1a2 (Mm00487224_m1), and Cyp1b1 (Mm00487229_m1) mRNA were determined using Taqman ${ }^{\circledR}$ Gene Expression assay (Applied Biosystems, Branchburg, NJ). Fold difference of mRNA expression was normalized to a reference 
gene (Gapdh, forward primer: CCTCGTCCCGTA GACAAAATG and reverse primer: TGAAGG GGTCGTTGATGGC) for each sample and calculated using $\Delta \mathrm{C}_{\mathrm{t}}$ method.

\section{Assay of hepatic microsomal CYP1 activity}

Microsomal fractions were prepared by ultracentrifugation of the homogenate-liver supernatants at $104,000 \times g$ at $4{ }^{\circ} \mathrm{C}$ for $1 \mathrm{~h}$. The concentration of microsomal protein was determined using the Bradford assay, with BSA as standard [8].

7-Ethoxyresorufin O-deethylase (EROD) and 7methoxyresorufin O-demethylase (MROD) activities represent CYP1 activity. A reaction mixture containing microsomal protein, and ethoxyresorufin (for EROD) or methoxyresorufin (for MROD) substrates in Tris-buffer ( $\mathrm{pH} 7.8$ ) were incubated at $37^{\circ} \mathrm{C}$. After adding NADPH, resorufin formation was kinetically measured at excitation and emission wavelength of 520/590 $\mathrm{nm}[8]$.

\section{Statistical analysis}

The data are presented as mean \pm S.D. and were analyzed using one-way ANOVA followed by Tukey post hoc test (IBM SPSS statistics version 23, Armonk, NY). $p<0.05$ was considered statistically significant.

\section{RESULTS}

Effect of styrene oxide (SO) and diethyl maleate (DEM) on hepatic toxicity and glutathione profiles

Mean mouse weight was not significantly changed by any treatments (data was not shown).

Table 1 shows plasma ALT and AST levels. After treatment for 7 days, SO and DEM (at the higher concentrations) significantly increased ALT, while AST was unchanged. After prolonged treatment for 14 days, SO markedly increased both ALT and AST levels, while DEM elevated only ALT. In contrast, NAC suppressed ALT levels compared to control. For long term treatment (28 days), neither DEM nor NAC changed ALT or AST levels, while both enzyme levels were increased by SO. These results reveal that SO and DEM caused hepatotoxicity, while NAC exerted hepato-protective effect after 14-days of treatment by reducing ALT levels.

Table 2 shows hepatic GSH profiles. After 7 days of treatment, total GSH and GSSG contents were raised by SO and DEM-350, which decreased the GSH/GSSG ratio in the SO treated mice. After prolonged treatment for 14 days, SO-150

Table 1: Plasma ALT and AST levels

\begin{tabular}{|c|c|c|}
\hline Group & $\mathrm{ALT}^{\star}(\mathrm{UI} / \mathrm{L})$ & $\mathrm{AST}^{\star \star}(\mathrm{UI} / \mathrm{L})$ \\
\hline Before treatment & $19.64 \pm 2.73$ & $23.13 \pm 2.81$ \\
\hline \multicolumn{3}{|l|}{ 7-day treatment } \\
\hline Control & $24.83 \pm 3.01$ & $22.11 \pm 2.59$ \\
\hline SO-150 & $29.20 \pm 3.52^{*}$ & $21.25 \pm 4.38$ \\
\hline SO-300 & $31.17 \pm 3.86^{*}$ & $23.85 \pm 3.80$ \\
\hline DEM-175 & $20.40 \pm 7.66$ & $23.24 \pm 3.31$ \\
\hline DEM-350 & $33.47 \pm 3.60^{*}$ & $22.11 \pm 2.06$ \\
\hline NAC-300 & $24.81 \pm 4.49$ & $18.94 \pm 1.10$ \\
\hline NAC-600 & $24.17 \pm 4.71$ & $19.41 \pm 2.83$ \\
\hline \multicolumn{3}{|l|}{ 14-day treatment } \\
\hline Control & $23.07 \pm 3.16$ & $25.06 \pm 3.90$ \\
\hline SO-150 & $33.34 \pm 4.87^{*}$ & $30.28 \pm 3.01^{*}$ \\
\hline SO-300 & $32.66 \pm 6.04^{*}$ & $29.17 \pm 3.14^{*}$ \\
\hline DEM-175 & $28.58 \pm 3.43^{*}$ & $25.57 \pm 6.25$ \\
\hline DEM-350 & $34.01 \pm 3.79^{*}$ & $26.15 \pm 5.26$ \\
\hline NAC-300 & $17.26 \pm 3.87^{*}$ & $23.37 \pm 6.13$ \\
\hline NAC-600 & $18.27 \pm 3.70^{*}$ & $23.08 \pm 2.63$ \\
\hline \multicolumn{3}{|l|}{ 28-day treatment } \\
\hline Control & $25.14 \pm 3.22$ & $21.95 \pm 4.39$ \\
\hline SO-150 & $30.63 \pm 4.55^{\star}$ & $26.33 \pm 2.35^{\star}$ \\
\hline SO-300 & $39.04 \pm 4.13^{*}$ & $27.89 \pm 4.18^{*}$ \\
\hline DEM-175 & $27.80 \pm 4.80$ & $24.69 \pm 4.49$ \\
\hline DEM-350 & $27.96 \pm 2.52$ & $22.10 \pm 2.01$ \\
\hline NAC-300 & $27.49 \pm 1.15$ & $22.60 \pm 4.78$ \\
\hline NAC-600 & $26.46 \pm 1.69$ & $22.85 \pm 4.03$ \\
\hline $\begin{array}{l}\text { *Alanine ar } \\
\text { aminotransferase; } \\
\text { period, based on } \\
\text { hoc test }\end{array}$ & transferase, & aspartat \\
\hline
\end{tabular}

increased GSSG content while SO-300 decreased total GSH and GSH content, resulting in a decrease in the ratio of GSH to GSSG. NAC600 also decreased total GSH, GSH and GSSG contents, but the GSH/GSSG ratio was not changed. In contrast, DEM increased total GSH, GSH (DEM-350 only) and GSSG contents without affecting the GSH/GSSG ratio. For the long-term 28-day treatment, high dose SO decreased GSH content., while high doses of DEM and NAC decreased total GSH, GSH and GSSG contents, leading to a decrease in the GSH/GSSG ratio for the high dose SO and DEM groups. These observations suggest that $\mathrm{SO}$ and DEM disturbed the GSH profiles, negatively affecting the anti-oxidative system via GSH depletion, presumably led to the liver damage seen in the ALT and AST assays.

\section{Effect of styrene oxide (SO) and diethyl maleate (DEM) on expression of Cyp1 mRNA}

At treatment for 7 days (Figure 1), SO (300 $\mathrm{mg} / \mathrm{kg} /$ day) significantly induced expression of Cyp1a1 (Figure 1 A), Cyp1a2 (Figure 1 B), and Cyp1b1 (Figure 1 C) mRNAs. Both doses of 
Table 2: Hepatic glutathione profiles

\begin{tabular}{lcccc}
\hline Group & $\begin{array}{c}\text { Total GSH } \\
\text { (nmoles/mg) }\end{array}$ & $\begin{array}{c}\mathbf{G S H}^{*} \\
\text { (nmoles/mg) }\end{array}$ & $\begin{array}{c}\text { GSSG } \\
\text { (nmoles/mg) }\end{array}$ & $\begin{array}{c}\text { Ratio of } \\
\text { GSH/GSSG }\end{array}$ \\
\hline 7-day treatment & & & & \\
Control & $57.09 \pm 0.69$ & $22.78 \pm 0.80$ & $34.30 \pm 0.23$ & $0.66 \pm 0.03$ \\
SO-150 & $73.33 \pm 0.20^{*}$ & $26.12 \pm 0.84$ & $47.21 \pm 0.64^{*}$ & $0.55 \pm 0.03^{*}$ \\
SO-300 & $69.13 \pm 0.79^{*}$ & $24.59 \pm 2.07$ & $44.54 \pm 1.32^{*}$ & $0.55 \pm 0.06^{*}$ \\
DEM-175 & $53.87 \pm 1.49$ & $19.32 \pm 1.97$ & $34.56 \pm 0.95$ & $0.56 \pm 0.07$ \\
DEM-350 & $66.41 \pm 1.23^{*}$ & $24.47 \pm 1.86$ & $41.94 \pm 0.69^{*}$ & $0.58 \pm 0.05$ \\
NAC-300 & $58.15 \pm 2.44$ & $21.60 \pm 2.73$ & $36.55 \pm 0.43$ & $0.59 \pm 0.08$ \\
NAC-600 & $56.79 \pm 2.03$ & $21.61 \pm 1.68$ & $35.18 \pm 0.40$ & $0.61 \pm 0.04$ \\
\hline 14-day treatment & & & \\
Control & $59.34 \pm 1.64$ & $22.41 \pm 1.31$ & $36.93 \pm 0.51$ & $0.61 \pm 0.02$ \\
SO-150 & $62.64 \pm 1.79$ & $21.69 \pm 0.55$ & $40.95 \pm 1.61^{*}$ & $0.53 \pm 0.02^{*}$ \\
SO-300 & $50.67 \pm 0.70^{*}$ & $16.84 \pm 1.10^{*}$ & $33.83 \pm 1.39$ & $0.50 \pm 0.05^{*}$ \\
DEM-175 & $66.13 \pm 1.08^{*}$ & $23.90 \pm 1.30$ & $42.23 \pm 0.51^{*}$ & $0.57 \pm 0.03$ \\
DEM-350 & $84.05 \pm 0.70^{*}$ & $31.91 \pm 0.52^{*}$ & $52.14 \pm 0.66^{*}$ & $0.61 \pm 0.01$ \\
NAC-300 & $58.30 \pm 1.77$ & $22.44 \pm 1.28$ & $35.87 \pm 0.57$ & $0.63 \pm 0.03$ \\
NAC-600 & $50.22 \pm 1.04^{*}$ & $19.44 \pm 1.21^{*}$ & $30.78 \pm 1.13^{*}$ & $0.63 \pm 0.06$ \\
\hline 28-day treatments & & & \\
Control & $54.31 \pm 1.05$ & $12.12 \pm 0.39$ & $42.19 \pm 0.72$ & $0.29 \pm 0.01$ \\
SO-150 & $54.40 \pm 0.91$ & $10.45 \pm 1.32$ & $43.97 \pm 1.17$ & $0.24 \pm 0.03$ \\
SO-300 & $50.88 \pm 0.10$ & $8.37 \pm 1.60^{*}$ & $42.51 \pm 1.61$ & $0.20 \pm 0.05^{*}$ \\
DEM-175 & $54.67 \pm 0.98$ & $10.82 \pm 1.69$ & $43.85 \pm 1.43$ & $0.25 \pm 0.05$ \\
DEM-350 & $40.47 \pm 0.37^{*}$ & $7.56 \pm 1.06^{*}$ & $32.90 \pm 0.70^{*}$ & $0.23 \pm 0.04^{*}$ \\
NAC-300 & $49.70 \pm 0.76$ & $10.67 \pm 0.89$ & $39.03 \pm 0.83$ & $0.27 \pm 0.03$ \\
NAC-600 & $38.07 \pm 0.43^{*}$ & $8.19 \pm 1.04^{*}$ & $29.89 \pm 0.62^{*}$ & $0.27 \pm 0.04$ \\
\hline NAC- & & & \\
\hline
\end{tabular}

"reduced glutathione, " oxidized glutathione; ${ }^{*} p<0.05$, vs control at the same duration, based on one-way ANOVA with Tukey post-hoc test

DEM markedly elevated expression of all Cyp1 mRNAs, while NAC did not modify expression of any isoform. The activities of EROD (Figure $1 \mathrm{D}$ ) and MROD (Figure $1 \mathrm{E}$ ) were increased by SO and DEM, corresponding to the increased expression of Cyp1 mRNAs.

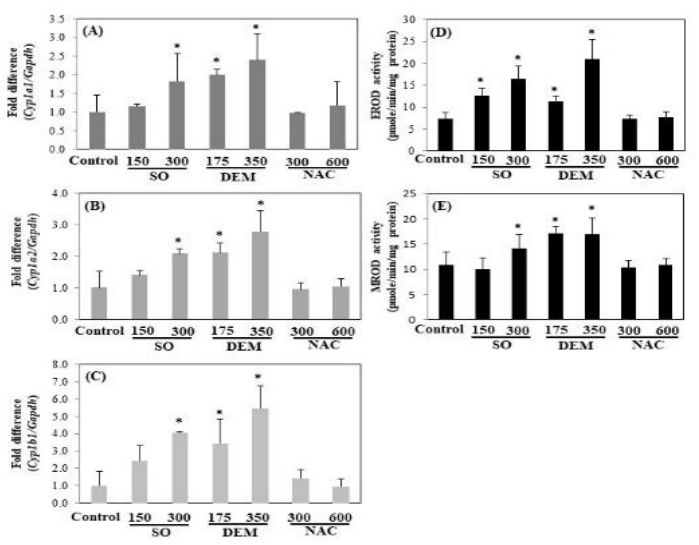

Figure 1: Effect of SO and DEM on the expression of Cyp1 after 7 day-treatment. Results are expressed as mean \pm SD of expression of Cyp1a1 (A), Cyp1a2 (B), Cyp1b1 (C) mRNAs, EROD activity (D), and MROD activity (E). ${ }^{*} p<0.05$, vs control based on one-way ANOVA with Tukey post hoc test

After prolonged treatment for 14 days, high dose SO $(300 \mathrm{mg} / \mathrm{kg} /$ day $)$ significantly induced expressions of Cyp1a1 (Figure 2 A), Cyp1a2
(Figure 2 B), and Cyp1b1 (Figure 2 C) mRNAs, while DEM at high dose (350 $\mathrm{mg} / \mathrm{kg} /$ day) only induced Cyp1a1 mRNA (Figure 2A). NAC did not alter expression of any Cyp1 isoforms. The activities of EROD (Figure 2 D) and MROD (Figure $2 \mathrm{E}$ ) were elevated by high dose $\mathrm{SO}$ and DEM, while NAC (600 mg/kg/day) suppressed EROD activity (Figure $2 \mathrm{D}$ ).

For the long-term treatment of 28 days, SO and DEM significantly induced expressions of Cyp1a1 (Figure 3 A), Cyp1a2 (Figure 3 B), and Cyp1b1 (Figure $3 \mathrm{C}$ ) mRNA, which corresponded with increased EROD (Figure 3 D) and MROD (Figure $3 \mathrm{E}$ ) activities. NAC did not change either the expression of any Cyp1 isoforms or the EROD and MROD activities.

\section{DISCUSSION}

Glutathione is the major non-enzymatic protective factor against oxidative stress in the liver [1]. Reduced glutathione (GSH) scavenges reactive oxygen species (ROS) and is transformed to GSSG by glutathione peroxidase, which is returned to $\mathrm{GSH}$ by glutathione reductase [1].

Suppression of glutathione activity has been shown to be involved in several abnormal conditions such as increased lipid peroxidation, pneumo-toxicity, liver steatosis, and Parkinson's 
disease. Moreover, GSH is crucial for detoxification of toxicants and carcinogens [9].

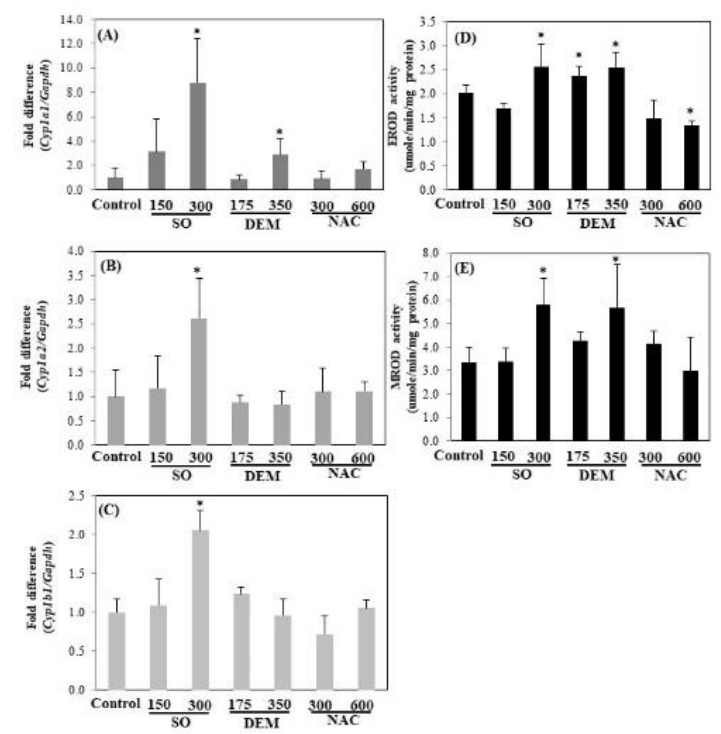

Figure 2: Effect of SO and DEM on the expression of Cyp1 after 14 day-treatment. Results are expressed as mean \pm SD of Cyp1a1 (A), Cyp1a2 (B), Cyp1b1 (C) mRNA expression, EROD activity (D), and MROD activity $(\mathrm{E}) .{ }^{*} p<0.05$, vs Control based on one-way ANOVA with Tukey post hoc test
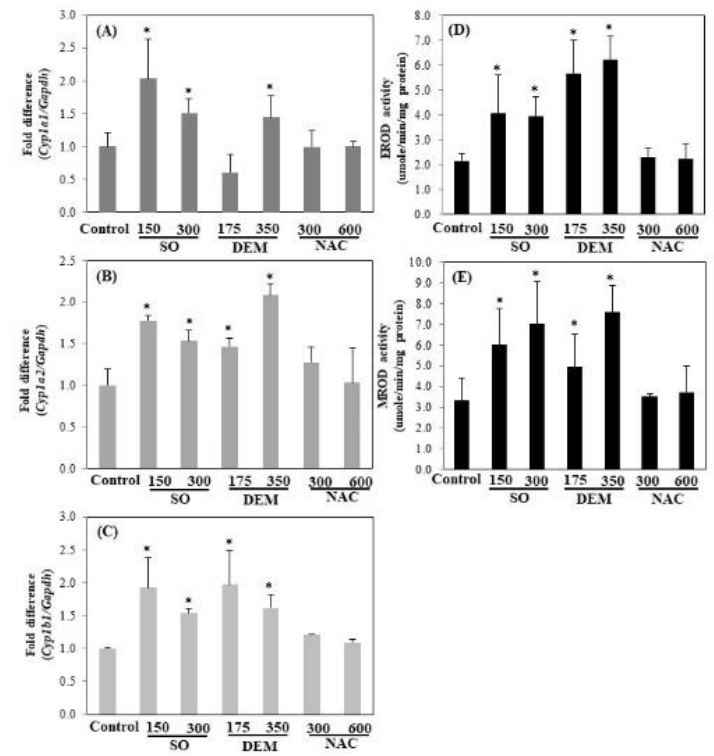

Figure 3: Effects of SO and DEM on the expression of Cyp1 after 28 day-treatment. Results are expressed as mean \pm SD of Cyp1a1 (A), Cyp1a2 (B), Cyp1b1 (C) mRNA expression, EROD activity (D), and MROD activity (E). ${ }^{*} p<0.05$, vs Control based on one-way ANOVA with Tukey post hoc test

Styrene has been used for plastic and resin production since 1940 [10]. Styrene vapor can be found in the air around manufacturing areas and can be a contaminant in drinking water. It is also found in cigarette smoke, coal tar, coal gas, and petroleum products produced by the organic molecule cracking process [10]. Styrene has been found in polystyrene micro-plastic products and is classified by the IARC as probably mutagenic due to its metabolite; styrene oxide (SO). The current study showed that SO suppressed the GSH profile in mouse livers, which agrees with a previous report that showed SO reduced GSH and GSSG levels in mouse lung and liver [11] and depleted GSH level in rat brain [12]. Diethyl maleate (DEM) is an environmental contaminant found as a pesticide metabolite and a component of plastic wrapper. DEM has also been shown to suppress GSH levels in rat brain and HepG2 cells [13]. N-AcetylL-cysteine (NAC) is a well-known GSH precursor. Consumption of NAC (100-300 $\mathrm{mg} / \mathrm{kg} / \mathrm{day}$, i.p. for 42 days) has been shown to exhibit antioxidant properties and reduce cholestasis-associated complications in rats [14]. Therefore, these three compounds were chosen as GSH modifiers in this study.

The CYP1 family consists of three isoforms, i.e. CYP1A1, CYP1A2, and CYP1B1. CYP1A1 and CYP1A2 are found mostly in the liver while CYP1B1 is found in extrahepatic organs, e.g. lungs, lymphocytes, mammary glands, and placenta [15]. The major function of the CYP1 family is the metabolism of exogenous compounds such as polycyclic aromatic hydrocarbons, which are broadly distributed environmental contaminants that cause carcinogenic, teratogenic, and immune toxicities in mammals [15]. In addition, the CYP1 family is implicated in the carcinogenic process. For example, CYP1A1 and CYP1B1 induction by cigarette smoke was shown to increase the risk of oral squamous carcinoma [16], and excessive CYP1A2 activity has been related to a higher risk of lung adenocarcinoma in Chinese women [17].

In this study, SO and DEM increased plasma levels ALT and AST, which are biomarkers for liver injury in humans and rodents. The GSH/GSSG ratio represents oxidative stress status and a decrease in this ratio indicates $\mathrm{GSH}$ depletion. Both SO and DEM decreased the GSH/GSSG ratio, while NAC did not. The lungs of rats exposed to styrene (750 ppm) for 4 weeks exhibited increases in malondialdehyde (MDA) levels, with associated decreases in catalase, superoxide dismutase, and GSH activities [18] and DEM has been shown to increase ROS levels in breast cancer [19]. The CYP1 inducer, benzo[a]pyrene induced EROD and glutathioneS-transferase activities in HT-29 colorectal cells [20]. The current study is the first that connects 
SO- and DEM-mediated up-regulation of Cyp1 expression with GSH depletion in mouse livers. Previously, polychlorinated diphenyl sulfides have been shown to induce CYP1A1 via the aryl hydrocarbon receptor $(A h R)$, causing overproduction of ROS in human HepG2 cells [21]. In this model, SO and DEM might cause excessive levels of ROS in the mouse livers leading to GSH depletion and Cyp1 upregulation. Thus, the mechanism of SO and DEM associated ROS production and the AhRmediated pathway for Cyp1 activation should be examined further.

\section{CONCLUSION}

Consumption of SO and DEM causes liver injury in mice with elevated ALT and AST levels, imbalance of GSH profile, and induction of Cyp1 mRNA. Exposure to these compounds increases the risk of carcinogenesis via GSH depletion and Cyp1 activation.

\section{DECLARATIONS}

\section{Acknowledgement}

Waranya Chatuphonprasert acknowledges the Thailand Research Fund (TRF) [Grant no. TRG5780272], the Commission on Higher Education (CHE), and Mahasarakham University, Thailand, for research funding and facilities. Dr Glenn Borlace, Khon Kaen University, Thailand, is acknowledged for English language assistance.

\section{Conflict of interest}

No conflict of interest is associated with this work

\section{Contribution of authors}

The authors declare that this study was done by the authors named in this article and that all liabilities pertaining to claims relating to the content of this article will be borne by them. WC designed the conceptual framework, carried out the experiments and statistical analysis, and drafted the manuscript. KJ supervised the experimental work, verified the data, proof read and revised the manuscript. The manuscript was comprehensively read and approved for publication by all authors.

\section{Open Access}

This is an Open Access article that uses a funding model which does not charge readers or their institutions for access and distributed under the terms of the Creative Commons Attribution License (http://creativecommons.org/licenses/by/ 4.0) and the Budapest Open Access Initiative (http://www.budapestopenaccessinitiative.org/rea d), which permit unrestricted use, distribution, and reproduction in any medium, provided the original work is properly credited.

\section{REFERENCES}

1. Forman HJ, Zhang H, Rinna A. Glutathione: Overview of its protective roles, measurement, and biosynthesis. Mol Aspects Med 2009; 30(1): 1-12.

2. Richardson RJ, Murphy SD. Effect of glutathione depletion on tissue deposition of methylmercury in rats. Toxicol Appl Pharmacol 1975; 31: 505-519.

3. Ekström T, Högberg J. Chloroform-induced glutathione depletion and toxicity in freshly isolated hepatocytes. Biochem Pharmacol 1980; 29(22): 3059-3065.

4. Troyano A, Fernández $C$, Sancho $P$, de Blas E, Aller $P$. Effect of glutathione depletion on antitumor drug toxicity (apoptosis and necrosis) in U-937 human promonocytic cells: The role of intracellular oxidation. J Biol Chem 2001; 276(50): 47107-47115.

5. Behrendorff JBYH, Gillam EMJ. Prospects for applying synthetic biology to toxicology: future opportunities and current limitations for the repurposing of cytochrome P450 systems. Chem Res Toxicol 2017; 30(1): 453468.

6. Touitou Y, Portaluppi F, Smolensky MH, Rensing L. Ethical principles and standards for the conduct of human and animal biological rhythm research. Chronobiol Int 2004; 21(1):161-170.

7. Sriset $Y$, Chatuphonprasert W, Jarukamjorn J. Bergenin exhibits hepatoprotective activity against ethanolinduced oxidative stress in ICR mice. Curr Top Nutraceut Res 2020; 18(3): 1-6.

8. Chatuphonprasert $W$, Rermraksakul P, Udomsuk L, Laoong $T$, Jarukamjorn $K$. Different profiles of hepatic alkoxyresorufin O-dealkylase activities in small rodents. J Appl Toxicol 2012; 32(12): 1002-1007.

9. Mytilineou C, Kramer BC, Yabut JA. Glutathione depletion and oxidative stress. Parkinsonism Relat Disord 2002; 8(6): 385-387.

10. Bansal A, Simon MC. Glutathione metabolism in cancer progression and treatment resistance. J Cell Biol 2018; 217(7): 2291-2298.

11. de Meester C, Poncelet F, Roberfroid M, Rondelet J, Mercier M. Mutagenicity of styrene and styrene oxide. Mutat Res Mol Mech Mutagen 1977; 56(2): 147-152.

12. Carlson GP, Turner M, Mantick NA. Effects of styrene and styrene oxide on glutathione-related antioxidant enzymes. Toxicol 2006; 227(3): 217-226.

13. Gille A, Turkistani A, Tsitsipatis D, Hou X, Tauber S, Hamann $I$, et al. Nuclear trapping of inactive FOXO1 by the Nrf2 activator diethyl maleate. Redox Biol 2019; 20: 19-27.

Trop J Pharm Res, February 2021; 20(2): 236 
14. Ommati MM, Amjadinia A, Mousavi K, Azarpira $N$, Jamshidzadeh A, Heidari R. N-acetyl cysteine treatment mitigates biomarkers of oxidative stress in different tissues of bile duct ligated rats. Stress 2020; 1-40.

15. Zanger UM, Schwab M. Cytochrome P450 enzymes in drug metabolism: Regulation of gene expression, enzyme activities, and impact of genetic variation. Pharmacol Ther 2013; 138(1): 103-141.

16. Nagaraj NS, Beckers S, Mensah JK, Waigel S, Vigneswaran $N$, Zacharias $W$. Cigarette smoke condensate induces cytochromes P450 and aldo-keto reductases in oral cancer cells. Toxicol Lett 2006; 165(2): 182-194.

17. Seow A, Zhao B, Lee EJD, Poh W-T, Teh M, Eng $P$, et al. Cytochrome P4501A2 (CYP1A2) activity and lung cancer risk: a preliminary study among Chinese women in Singapore. Carcinogenesis 2001; 22(4): 673-677.

18. Haghighat $M$, Khavanin A, Allameh A. Oxidative stress indices in rats' lung tissues following simultaneous exposure to noise and styrene $J$ Occupational Health Epidemiol 2017; 6(1): 1-8.

19. Čolović $M$, Yang $H$, Merkens $H$, Colpo $N$, Bénard $F$, Schaffer $P$. Non-invasive use of positron emission tomography to monitor diethyl maleate and radiationinduced changes in system $X_{c-}$ activity in breast cancer. Mol Imaging Biol 2019; 21(6): 1107-1116.

20. Ghazali AR, Lee WX, Cheng $X$ yi, Ahmad A, Nagapan TS. Effects of pterostilbene on activities and protein expression of cytochrome P450 1A1 (CYP1A1) and Glutathione s-transferase (gst) in benzo[a]pyreneinduced HT-29 colorectal cancer cell line. Malaysian J Heal Sci 2018; Available from: http://ejournals.ukm.my/jskm/article/view/23986

21. Liu H, Shi L, Giesy JP, Yu H. Polychlorinated diphenyl sulfides can induce ROS and genotoxicity via the AhRCYP1A1 pathway. Chemosphere 2019; 223: 165-170. 